\title{
De rol van sociaal tolk in de maatschappij
}

\begin{abstract}
In this article, the question of different roles that community interpreters play in the context of interpreted interactions is addressed, or rather how these roles are perceived. The fact that interpreters function as mediators of pronouncements from one language to another (and vice versa) is apparent from the nature of the interpretation process itself. However, frequent studies by contemporary researchers in this field show that the role of community interpreter is clearly different from that of conference interpreter; the role of the community interpreter, as seen by several authors, often goes beyond the mediation of the language transfer of necessary information, and the interpreter is often even considered responsible for the coordination of a particular conversation between participants of interpreted communication: the community interpreter determines who is speaking and who is listening; explains to the participants what the other party mean; signals this; and explains why a certain interpreted communication was not understood by one of the parties. The specific cultural position of the interpreter can sometimes also be the reason why the interpreter "leaves his mediating role". Interpreters always operate between two worlds which are different at different levels and which it is precisely the interpreter's job to connect through the language transfer of communications. In the case of community interpreters, we often have to deal with striking differences in norms and values. Does the interpreter have to inform the participants of the interaction about these differences or not? Doesn't he go too far if he actively intervenes in conflict situations in an interpreted dialogue, because the other participant doesn't have the necessary knowledge about the cultural traditions and customs of the other party? Can we expect the interpreter to inform his client, who does not speak the language of the country in question, of his rights as soon as he notices that the other party does not respect them?

The article discusses various insights into the role played by community interpreters. We start from the hypothesis that the perception of the role of the community interpreter will be highly dependent not only on different conceptual representations of individual authors but will also be differently anchored in different countries and cultures.
\end{abstract}

Keywords: community interpreting, cultural mediation, multilingualism, interpreting studies, language transfer. 


\section{Inleiding}

Oudere studies gericht op de uitoefening van het beroep van sociaal tolk gingen uit van de klassieke rol voorgeschreven voor conferentietolken. Het vertrekpunt hierbij is dat de tolk een neutrale rol van een bemiddelaar inneemt die, zonder enige buiten-talige ingreep, informatie uit taal A naar taal B transformeert. Het moderne onderzoek verschuift stapsgewijs naar een stadium, waarbij zichtbaar wordt dat deze idealistische opvatting niet realistisch is en meerdere auteurs onderstrepen het tegenovergestelde, namelijk dat sociaal tolken meer invloed hebben op het verloop van getolkte interacties dan dat we zouden kunnen verwachten in overeenstemming met dit ideaal.

\footnotetext{
For many years, interpreters have too often hidden behind the cloak of neutrality, avoiding the realization that taking no action can be as harmful as an inappropriate action. It will only be possible to develop best practices related to role when interpreters recognize and accept responsibility for the power they have as participants and co-constructors of meaning in an interpreted interactive event. (Swabey \& Gajewski Mickelson 2008: 69).
}

Doornbos (2006: 240) ${ }^{1}$ beschouwt het idee van de volstrekt neutrale tolk als een "mythe". Ze geeft aan dat elke vertaling uitkomst is van het interpretatieproces van een tolk. Deze interpretaties worden door sociale en culturele conventies van de tolk beïnvloed, maar ook door zijn persoonlijke kennis, verwachting en gedrag. Hoewel deontologische codes aan (sociaal) tolken een strikt neutrale rol voorschrijven, blijkt uit de meerderheid van uitgevoerd onderzoek (Kaufert \& Putsch 1997; Bot 2003; Roy 2000; Wadensjö 1998), met betrekking tot de rol van sociaal tolken, dat de tolk in getolkte gesprekken veel actiever optreedt; eerder als een derde partij. De opvatting over de rol van de tolk is eveneens afhankelijk van zijn officiële maatschappelijke status en positie in het rechtssysteem van desbetreffend land.

Bijvoorbeeld in België is sociaal tolk sinds 2007 een duidelijk afgebakend beroep dat ook juridisch verankerd is, hetgeen nauw samenhangt met de voortdurende toestroom van arbeidsmigranten en asielaanvragers. In Centraal-Europa komt het vakgebied sociaal tolken pas langzaam tot ontwikkeling en kunnen we nog niet van een officieel gedefinieerd vakgebied spreken wat ook gereflecteerd wordt in onduidelijkheden rondom de rol, competenties en verantwoordelijkheid van de sociaal tolk.

\section{Rolafbakening sociaal tolk}

Wat is eigenlijk de taak van sociaal tolk? Is het slechts communicatiebemiddeling tussen twee partijen die niet dezelfde taal spreken of komen sociaal tolken nog

\footnotetext{
${ }^{1}$ N. Doornbos, Op verhaal komen: institutionele communicatie in de asielprocedure.
} 
dichterbij hun klanten, resp. de andere partij, dan conferentietolken? De vraag van de rol van de sociaal tolk hoort al vanaf het begin tot de meest bediscussieerde en omstreden kwesties op dit gebied (Bancroft 2015: 225). ${ }^{2}$ Onduidelijke competenties kunnen verwarrend zijn voor de tolken en hun klanten en kunnen ook serieuze misverstanden en complicaties veroorzaken. Maar de diversiteit van het gebied verhindert duidelijke afbakening van de rol die een van de basisvoorwaarden vormt voor professionalisering (Holkupová 2010: 11). Als gevolg daarvan heerst onenigheid over de rol van de sociaal tolk onder vakmensen en ook de verwachtingen van klanten (deelnemende partijen) zijn vaak zeer uiteenlopend en niet altijd reëel (Diabová 2014: 4). De basisverdeling van de competenties en rollen van sociaal tolken is gegrond op twee modellen die we nader bespreken.

\subsection{Monologisch model sociaal tolk}

Het monologisch (normatief) tolkmodel gaat uit van de klassieke rol voorgeschreven voor de conferentietolk en is gebaseerd op de veronderstelling dat de interactie tussen de deelnemers een eenrichtingsproces is, waarbij informatietransfer tussen hen tot stand wordt gebracht. De sociaal tolk wordt volgens dit model geacht om uitsluitend als een kanaal te functioneren en een accurate vertaling te produceren. Daarom wordt deze rol met een neutrale, haast afwezige en bijna machinale non-person vergeleken (Pöchhacker 2004: 147). Deze opvatting van de rol wordt echter veel bekritiseerd (zie Wadensjö 1998; Angeletti 2004; Pöchhacker 2004; Holkupová 2010; Diabová 2014; Bancroft 2015; Gentile 2017), en zelfs als achterhaald en ongewenst beschouwd omdat deze zelden met de werkelijkheid overeenstemt.

\subsection{Dialogisch model sociaal tolk}

Met groeiende belangstelling voor het vakgebied sociaal tolken wordt de opvatting van een andere rol van de sociaal tolk door meer en meer auteurs geaccepteerd. Hiermee wordt het dialogisch (descriptief) model bedoeld. De tolk krijgt in dit communicatiemodel een actievere en belangrijkere rol toebedeeld wat ook met de concrete communicatieve situatie samenhangt, waarin zijn rol kan veranderen.

Soms wordt aan de tolk door de deelnemers van de getolkte interactie een rol verleend die zijn reële mogelijkheden te boven gaat. Bijv. Anderson (1976: 216), die het tolkproces onderzocht heeft vanuit het sociologische perspectief, spreekt van de tolk als van man in the middle, omdat deze zich tussen twee primaire deelnemers van de interactie bevindt, en wijst erop dat de tolk een cruciale positie heeft want zonder hem zou de communicatie onmogelijk zijn. Dankzij deze exclusieve positie heeft de tolk ruimte om zelf zijn rol te definiëren en beïnvloedt

${ }^{2}$ Maar ook bijv. C. Angeletti, F. Pöchhacker, R. De Keyser, E. Hertog, C. Wadensjö, S.B. Hale. 
zijn gedrag sterk de structuur en het verloop van de getolkte communicatie. Hoewel deze opvatting als overdreven kan overkomen, is het duidelijk dat sociaal tolken die in een directe communicatie tolken tussen een kleiner aantal personen, volwaardigere deelnemers van de communicatie zijn dan de conferentietolken die vanuit een geïsoleerde tolkcabine tolken en geen actieve rol in de interactie innemen. Een belangrijk differentiërend kenmerk van sociaal tolken ten opzichte van conferentietolken is ook het feit dat de monologische opvatting van de communicatieve situatie onvoldoende is omdat de betekenis van een mededeling niet alleen door de auteur wordt aangegeven maar medegevormd wordt door alle deelnemers van de communicatie. Het betreft een gezamenlijke interactie van afzonderlijke deelnemers in het kader van een sociale context, wat kenmerkend is voor het dialogisch communicatiemodel (Wadensjö 1998: 153). De tolk die tussen twee partijen zit kan en moet het gesprek soms als het ware coördineren (Wadensjö 1998: 153), wat bijv. het afhandelen van overlappende uitingen of modereren van spreekbeurten en onderwerpen aangaat. Vanwege de controle over de informatiestroom gebruikt Wadensjö (1998: 67-68) de term gatekeeper.

Wadensjö onderbouwt haar opvatting van de positie van de tolk op een sociologische basis. In tegenstelling tot situaties waarin de partijen direct met elkaar kunnen spreken, functioneert de tolk in door hem bemiddelde interacties eerder als een verbindingsschakel die de communicatie herstelt. Het beeld van de sociaal tolk als een actievere deelnemer wordt ook door Pöchhacker ondersteund (2004: 88), die de rol van de tolk in het midden tussen twee partijen ziet als: "[...] more or less active participant in the interaction rather than a mere "switching station"".

Een andere reden waarom de sociaal tolk niet slechts als een passief werktuig $^{3}$ beschouwd kan worden, is het feit dat sociaal tolken meestal niet alleen tussen talen maar ook tussen culturen moeten tolken. Dat wil zeggen dat een correcte vertolking ook de interculturele context en de context van communicatie in acht dient te nemen, maar ook de impact daarvan moet overbrengen. Van de sociaal tolk wordt verwacht om tussenbeide te komen vooral in het geval van communicatiebarrières of misverstanden, niet om culturele of andere problematiek toe te lichten (Bancroft 2015: 226).

\subsection{Tot waar strekt de rol van sociaal tolk}

Hoewel vandaag de dag de meeste auteurs die over sociaal tolken publiceren het met elkaar eens zijn dat sociaal tolken tijdens de getolkte interactie een belangrijke actieve rol speelt, verschillen vaak hun concrete opvattingen erover, wat hun rol nog wel en wat niet meer inhoudt De afzonderlijke theorieën verschillen

3 Ook Hale (2007: 42) stelt dat de rol van de tolk als een "vertaalmachine" die alleen letterlijke vertalingen produceert noodzakelijkerwijs tot onnauwkeurigheid leidt, omdat deze geen rekening houdt met alle belangrijke aspecten van de interactie. 
verder qua diverse institutionele en sociale condities waarbinnen de getolkte interactie plaatsvindt.

Wadensjö (1998: 105) heeft onderzocht hoe sociaal tolken een getolkte interactie van deelnemers actief kunnen coördineren en op deze manier een actieve communicatieve rol vervullen. In haar opvatting heeft de tolk een tweevoudige rol: de taaltransfer van een taal naar een andere en de coördinatie van de communicatieve situatie, waarbij hij erin ingrijpt en derhalve een directe invloed heeft op het verloop ervan. De tolk kan aangeven, wie wanneer het woord moet krijgen, wanneer het nodig is om een pauze te maken en kan uitdrukken dat een van de partijen te snel praat, en dergelijke. Door deze actieve bezigheid draagt de tolk bij aan een kwalitatievere communicatie tussen deelnemers en overbrugt verschillen niet alleen op taalniveau maar ook qua cultuur. De communicatie kan door de tolk nog explicieter worden beïnvloed, wanneer hij de spreker onderbreekt of om verduidelijking vraagt of meer ruimte vraagt voor de vertolking of op een andere manier al vertolkte mededelingen becommentarieert. Hij kan de afzonderlijke sprekers er ook op wijzen dat ze bepaalde informatie niet verschaft hebben, terwijl deze door de andere spreker werd gevraagd. Impliciet kan de tolk de getolkte communicatie beïnvloeden door het parafraseren van de oorspronkelijke informatie, door samenvatten, aanvullen of weglaten. Deze extreem actieve coördinerende rol wordt aan de sociaal tolk ook bijvoorbeeld door Angelelli (2003), Pöchhacker (2000) of Pöllabauer (2004) toegekend.

Angelelli (2003) noemt zelfs voorbeelden wanneer de tolk, traditioneel beschouwd als onpartijdig, uit zijn neutrale rol stapt en een van de deelnemende partijen kiest, wat niet altijd als ongewenst wordt ervaren (Pöllabauer 2004: 175). In de gezondheidszorg hebben we vaak te maken met asymmetrie tussen partijen (aan de ene kant een lid van de minderheidscultuur in het desbetreffende land, aan de andere kant de arts als lid van de meerderheidscultuur; de sociaal tolk neemt de benadeelde positie van het lid van de minderheidscultuur waar en kan het gevoel hebben dat het zijn taak is om zijn belangen te verdedigen, om de situatie enigszins te 'compenseren'. Tolken kunnen ook de andere partij 'kiezen', indien ze bijvoorbeeld regelmatig voor een bepaalde instelling werken. Ze kunnen de situatie vaak niet mijden, waarin ze zich tot een bepaalde hoogte met de instelling beginnen te identificeren en voor de andere partij als vertegenwoordigers ervan optreden, bijvoorbeeld voor een asielaanvrager bij de immigratiedienst (zie bijv. Pöllabauer 2004: 175). Of we deze aanpak door sociaal tolken nog als legitiem kunnen beschouwen, is de vraag. De manier waarop hiermee omgegaan wordt, is sterk afhankelijk van de ervaring en praktijk met sociaal tolken in het gegeven land. Het spreekt voor zich dat een dergelijk gedrag van de tolk het kader overschrijdt, waarbinnen hij zich zou moeten bewegen en ook zijn competenties te boven gaat. Het falen van tolken die tijdens hun werk op deze manier optreden kan ook met het feit samenhangen dat hun rol soms verward wordt met een ander beroep, name- 
lijk de intercultureel bemiddelaar. De taak van de intercultureel bemiddelaar is in tegenstelling tot de sociaal tolk om potentiële interculturele conflicten te bemiddelen, waarbij ze ook kunnen tolken. Intercultureel bemiddelaars dienen verder o. a. getraind te zijn m. b. t. communicatieprincipes, beginselen van onderhandelingspraktijken en dergelijke. Bovendien kunnen ze ook emotionele ondersteuning bieden en actief in een bepaalde interactie ingrijpen om de belangen van de partij die ze dienen te ondersteunen te verdedigen (Figarová 2012: 11).

\section{Verschillende rollen van de sociaal tolk}

Als we de hierboven geschetste bevindingen samenvatten, kunnen we de volgende rollen definiëren, die sociaal tolken kunnen vervullen in de maatschappij en die elkaar kunnen aanvullen afhankelijk van de gegeven communicatieve situatie en de sociale context van het getolkte gesprek.

- rol van neutraal communicatie instrument dat alleen zo relevant mogelijk de medegedeelde informatie van een taal naar een andere overbrengt; ${ }^{4}$

- rol van impliciete communicatie coördinator (die het woord aan afzonderlijke deelnemers geeft, mogelijke misverstanden aanwijst, om aanpassing van het spraaktempo vraagt en dergelijke);

- rol van expliciete communicatie coördinator (die ook de inhoud of vorm van getolkte informatie corrigeert, doordat deze de taal vereenvoudigt, terwijl hij naar de doeltaal tolkt en hiermee de communicatie duidelijker en ook effectiever maakt);

- rol van interculturele specialist (indien nodig verduidelijkt hij mededelingen, het doel is vooral om conflicten te voorkomen, gebaseerd op verschillende culturele tradities);

- rol van specialist in het gegeven gebied (die regelmatig tolkt in een bepaald vakgebied en zich derhalve oriënteert en, indien door de vertegenwoordiger van de instelling gevraagd, uitleg kan geven);

- rol van belangenverdediger van een van de discours deelnemers (tolk treedt op in de rol van a) belangenverdediger van de vreemdeling of b) hulp van de instelling).

\subsection{Algemene opvattingen over de rol van de tolk}

Wegens onenigheid van opvattingen rondom de rol van de sociaal tolk is het niet gemakkelijk om de voorstellingen over de uitoefening van deze rol te unificeren,

${ }^{4}$ Deze rol wordt door de meerderheid van de auteurs als vanzelfsprekend beschouwd en daarom houden ze zich hiermee in hun empirische onderzoek niet bezig en besteden de aandacht eerder aan andere rollen die het kader van de neutrale taaltransfer overschrijden. 
ook al richten we de aandacht direct op afzonderlijke acteurs van de discoursen binnen sociaal tolken. Net zo schijnt de verwachting dat sociaal tolken in staat zijn om meerdere rollen tegelijk te vervullen, zie hierboven, voor tolken nogal veeleisend. ${ }^{5}$ Verschillende eisen gesteld aan tolken door afzonderlijke instellingen of andere partijen, die gebruik maken van hun diensten, leiden tot groei van de druk waaronder sociaal tolken werken en dragen op die manier niet tot de effectiviteit van het uitvoeren van hun werk bij. Daarom lijkt het wenselijk een poging te wagen om deze verwachtingen of voorstellingen tenminste in grote lijnen te standaardiseren.

Sinds 2000 werd een aantal empirische onderzoeken uitgevoerd (Pöchhacker 2000; Angelelli 2003; Pöllabauer 2004; Leanza 2005; Holkupová 2010) die zich bezig hielden met de waarneming van de rol van de sociaal tolk boven het kader van de taaltransfer. Door middel van enquêtes gericht tot vertegenwoordigers van instellingen die diensten van sociaal tolken afnemen, als ook sociaal tolken zelf die in verschillende contexten werkzaam zijn (meestal in de gezondheidszorg ofwel asielprocedure), hebben auteurs een set rollen onderzocht die sociaal tolken uitoefenen en hebben de 'zichtbaarheid' ofwel 'onzichtbaarheid' van sociaal tolken bekeken door de ogen van betrokkenen (Angelelli 2003: 16) ${ }^{6}$. De gemeenschappelijke conclusie van de onderzoeken is het feit dat de grote meerderheid van respondenten de rol van de sociaal tolken als vrij breed beschouwt, hetgeen ook voor tolken geldt die hun eigen rol zelf moesten beoordelen. In het volgende gedeelte gaan we de voorstellingen over de rol van de sociaal tolk apart bekijken, vanuit het perspectief van de instellingen en vanuit het zicht van de tolken.

\subsubsection{Voorstellingen van instellingen}

Uitgaande van oudere werken wordt het inschakelen van een tolk door de vertegenwoordigers van instellingen eerder als negatief waargenomen, sommigen spreken zelfs van "nodig kwaad" (Wandenjö 1998). De activiteit van de tolk wordt in een concrete getolkte communicatie als storend beschouwd en veel medewerkers van instellingen schijnen de tolken met een bepaald wantrouwen te bezien. Deze inzichten zijn gebaseerd op de invloed van het monologisch normatief model op getolkte communicatie dat in de vakliteratuur tot voor kort het overwicht had en dat niet te veel betekenis aan de tolk verleende. De rol van de tolk wordt gereduceerd tot de taaltransfer van taal A in taal B. Dit model is ook in overeenstemming met het idee van de meeste mensen dat door de conferentietolk wordt belichaamd, waarbij de tolk slechts een instrument voor bemiddeling van informatie is.

5 Pöllabauer (2004: 175) gebruikt in dit verband de term role overload.

${ }^{6}$ Interessant was ook de conclusie van Angelelli dat zichtbaarheid van sociaal tolken veel groter is dan de zichtbaarheid van tolken betrokken in andere contexten dan de sociale, di conferentie- en gerechtstolken. 
Nieuwere werken bevestigen eerder de omgekeerde opvatting, er wordt veel meer van de tolk verwacht dan pure vertolking van uitgesproken mededelingen, de rol van de tolk wordt soms zelfs overschat en er worden uitingen getolereerd die niet in een lijn zijn met de algemeen geëiste neutraliteit, waarvoor de tolk zou moeten staan (Pöllabauer 2004).

\subsubsection{Voorstellingen van tolken}

Uit vergeleken onderzoeken is gebleken dat noch conferentietolken, noch gerechtstolken zich als onzichtbaar beschouwen (Angelelli 2003). De tolken in het algemeen begrijpen hun rol breder dan als een machinale rol beperkt tot taaltransfer. Toch is er ook bij deze groep respondenten een merkbare tegenstrijdigheid in het begrijpen van de rol van de tolk. Ook tolken zijn beïnvloed door de jarenlang algemeen geldige opvatting dat ze als passieve bemiddelaars zouden moeten functioneren en ze zich zouden moeten houden aan basisregels vastgesteld voor (conferentie-) tolken. Bij deze regels horen in de eerste instantie onpartijdigheid, loyaliteit en nauwkeurigheid. Tot een interessante conclusie kwam in zijn onderzoek Leanza ${ }^{7}$ (2005: 171) die aangeeft dat de door hem bevraagde sociaal tolken het als het meest frustrerend hebben beschouwd dat hun rol gereduceerd was tot een pure bemiddelaar van in taal vervatte mededelingen, tegelijkertijd zien ze deze rol echter als de meest voorkomende, die ze tijdens gesprekken tussen patienten en arts hebben vervuld. Als het meest bevredigend hebben de tolken hun rol beschouwd waarbij ze als een tweetalige specialist hebben gefunctioneerd, waarbij ze eerder vakkundige zaken met de arts hebben besproken die eigenlijk niets te maken hadden met het tolken op zich.

Een duidelijkere oriëntatie van sociaal tolken met betrekking tot de rol, die ze in de maatschappij zouden moeten vervullen, zou vereenvoudigd moeten zijn door algemeen geldige professionele en deontologische regels die deze rol zouden codificeren. De institutionalisering van het vakgebied sociaal tolken is nog steeds niet overal goed verankerd, met name in de landen van Centraal-Europa. We zullen hierop dieper ingaan in het volgende gedeelte.

\subsection{Competente sociaal tolk}

Vanwege het gebrek aan duidelijke afbakening en algemeen uiteenlopend begrip van de rol van de sociaal tolk is het moeilijk om basisvereisten vast te stellen die we op de uitoefenaars van dit beroep kunnen toepassen. De situatie is des te erger omdat er nog steeds veel landen zijn, waar sociaal tolken nog steeds geen

7 De psycholoog Y. Leanza (2005) onderzocht in zijn onderzoek de rol van de tolk in het kader van preventieve controles bij de kinderarts in het Franstalige deel van Zwitserland. 
geaccrediteerd studievak is en het aanbod van gespecialiseerde cursussen op dit gebied onvoldoende is. Wat zijn eigenlijk de competenties, waarover sociaal tolken zouden moeten beschikken?

Een gekwalificeerde sociaal tolk zou in staat moeten zijn om in elke communicatie in de gegeven taalcombinatie te bemiddelen, vooral gerelateerd aan de sociale context en gebruikelijke terminologie. De tolk moet naar zijn klanten kunnen luisteren en hun problemen onder woorden kunnen brengen. Hij zou in staat moeten zijn om met mensen samen te werken die zich in een emotioneel beladen en stressvolle situatie bevinden en vaak naar de tolk kijken als naar hun hulp omdat ze beseffen dat ze van hem afhankelijk zijn. Vaak zijn het ook mensen die geen ervaring met tolken hebben en hun verwachting kan verder gaan dan wat de reële mogelijkheden van de tolk zijn. De tolk zou de verantwoordelijkheid voor het slagen van de hele handeling op zich moeten kunnen nemen (Nakládalová 2007: 18). Hij moet de spanning kunnen doorbreken, gespannen situaties kunnen overwinnen en sociale en culturele verschillen weten te overbruggen.

Een onafscheidbaar onderdeel van de praktijk van de sociaal tolk is ook de interculturele communicatie. De tolk die mensen van verschillende nationaliteiten, culturen, religies en etnische afkomstent ontmoet, moet zich thuis voelen in verschillen die met hun diverse herkomst en achtergrond samenhangen. De onbekendheid met cultureel specifieke omstandigheden kan gemakkelijk in een interculturele barrière uitmonden die door de taalbarrière wordt gemanifesteerd. Een belangrijk kenmerk van elke cultuur zijn tradities en specifieke waarden die geërfd worden van generatie op generatie. Deze gedeelde gemeenschappelijke waarden en tradities veranderen met tijd in maatschappelijke normen en standpunten.

Het is niet voldoende voor de tolk om te beschikken over een uitstekende kennis van desbetreffende talen en diepere linguïstische structuren, noodzakelijk is ook de kennis van de interculturele communicatie (en specifieke interculturele verschillen), die ook de non-verbale communicatie omvat. Grote verschillen zijn o.a. te vinden in gesticulatie en mimiek van leden van diverse culturen. Als de tolk niet bekend is met de achtergrond van deze verschillen, zou hij in situaties terecht kunnen komen, waar onnodig misverstanden ontstaan of zelfs minachting. Een tolk die over de interculturele competentie beschikt, kan wederzijds respect van partijen bevorderen.

De sociaal tolk moet rekening houden met specifieke behoeftes van bepaalde groepen voor wie hij tolkt. Dat kunnen bijvoorbeeld vrouwen zijn die een traumatische ervaring hebben meegemaakt, omdat ze moeite hebben om over hun ervaring te praten. Andere specifieke omstandigheden kunnen zich voordoen, wanneer er voor minderjarigen wordt getolkt. Ook in zulke situaties zou de tolk echter de neiging moeten weerstaan om als hulp of beschermer van de minderjarige klant te functioneren. 


\subsection{Rol van sociaal tolken volgens ISO norm}

Hoewel de internationale ISO norm 13611:2014 ${ }^{8}$ Tolkdiensten - Richtlijnen voor sociaal tolken geen juridische geldigheid heeft, is het interessant om het hierboven geschetste kader te vergelijken met de inhoud van deze norm die in hoofdstuk zeven juist de rol van sociaal tolken bespreekt.

In de kern van deze norm wordt benadrukt dat de sociaal tolk aan de ene kant zijn rol dient te beperken tot sociaal tolken en geen eigen advies mag aanbieden of in de rol van adviseur optreden, aan de andere kant behoort hij in te grijpen, wanneer hij het gevoel heeft dat er een culturele barrière ontstaan is en daarom een misverstand. In een dergelijke situatie moet hij echter niet uitleggen, waarom het misverstand ontstaan is, hij behoort te focussen op de identificatie ervan en mogelijk op de onderbreking van het tolkproces. Een ander belangrijk punt is het herkennen en vervolgens vertolken van de interculturele verschillen en non-verbale communicatie. Impliciet ingrijpen van de sociaal tolk komt overeen met de hierboven gemaakte bevindingen in die zin dat de sociaal tolk bijvoorbeeld de communicatiestroom kan besturen, doordat hij een te snel spraaktempo van een van de deelnemers van de getolkte communicatie aangeeft of om verduidelijking van een term vraagt die gebruikt werd. De ISO norm Sociaal tolken is over het algemeen in een lijn met de bevindingen van het huidige onderzoek rondom de rol van de sociaal tolk, dat hierboven gereflecteerd werd.

\subsection{Rol sociaal tolken deontologie - Vlaanderen}

Een van de landen, waar sociaal tolken een lange traditie heeft, een goed ontwikkeld wetenschappelijk vakgebied is geworden en sinds 2007 zelfs een officieel erkend beroep is, is België. Het Agentschap Integratie en Inburgering is verantwoordelijk voor de opleiding en certificering van sociaal tolken in Vlaanderen (www1). In 2017 heeft het Agentschap een deontologische code ontworpen, waaraan zich alle gecertificeerde sociaal tolken in Vlaanderen moeten houden.

In deze code wordt de rol van de sociaal tolk veel strikter en smaller genomen. De basisprincipes, die bindend zijn voor de sociaal tolk, omvatten: discretie, neutraliteit, volledigheid, transparantie en een professionele houding. De rol van de sociaal tolk is hoofdzakelijk beperkt tot de taaltransfer en er wordt nauwelijks ruimte aan de tolk verleend om in het getolkte gesprek in te grijpen. Met de volledigheid wordt bedoeld dat: "de tolk heeft de plicht alles wat door de partijen wordt gezegd volledig en getrouw te tolken zonder iets toe te voegen, weg te laten of te wijzigen" (www2).

${ }^{8}$ NEN-ISO 13611:2014 en Tolken- Richtlijnen voor sociaal tolken. 
In het kader van de transparantie kan hij wel om verduidelijking vragen, maar hij heeft altijd de plicht om dit aan de partijen te melden. Met betrekking tot de professionele houding moet hij aan het begin van elke tolkopdracht tegen de partijen zeggen wat zijn rol is, d. w. z. alleen de vertolking. Zijn neutraliteit moet hij niet alleen tijdens de tolkopdracht bewaren maar ook vóór en na de opdracht.

Een dermate strikte code zorgt ervoor dat sociaal tolken goed gefocust zijn op hun werk en niet afgeleid worden door andere aspecten van het gesprek. De vraag is of overheden, bijvoorbeeld in de landen van Centraal-Europa, waar dit vakgebied nog geprofessionaliseerd en geïnstitutionaliseerd moet worden, een dergelijk strikt model zullen volgen of niet. Zeker voor sociaal tolken die weinig werkervaring hebben en geen gespecialiseerd opleidingstraject hebben gevolgd voor dit beroep, waarborgt een duidelijk afgebakende deontologische code een betere basis voor de levering van professionele diensten en de ontwikkeling van dit vakgebied.

\section{Slot}

De rol van de tolk is, in het kader van onderzoek gericht op sociaal tolken, een veel bediscussieerd onderwerp, wat vooral met zijn specifieke sociale en culturele positie tijdens het uitoefenen van zijn beroep samenhangt. Zijn taak is het realiseren van communicatie tussen twee werelden die niet dezelfde taal spreken en geen gelijke culturele en sociale achtergrond hebben. Er bestaan twee basis conceptuele modellen voor de afbakening van de rol van de sociaal tolk. Een de ene kant kunnen we de tolk beschouwen als een actieve deelnemer van een triadistische getolkte interactie. Aan de andere kant wordt het begrip van de neutraliteit van de tolk benadrukt, gebaseerd op deontologische codes en verwachtingen van andere deelnemers van de getolkte interactie. Het gevolg van deze discrepantie is dat tolken zelf met de afbakening van hun rol en verantwoordelijkheid zitten te kampen.

De rol van de sociaal tolk is ingewikkeld in die zin dat de tolk verantwoordelijk is voor een getrouwe en accurate transfer van mededelingen tussen deelnemers van een gesprek, maar hierbij zijn neutraliteit dient te bewaren. Concreet betekent dat dat de tolk geen nieuwe onderwerpen zou moeten openen, deze wijzigen, hij mag zijn eigen mening niet laten blijken, en geen advies verstrekken. De uitoefening van het beroep van de sociaal tolk gaat vaak gepaard met overdreven eisen gesteld aan de tolk van wie verwacht wordt dat hij allerlei functies zal bekleden die niet reëel zijn. Bovendien kan een centrale positie van de tolk tussen de andere deelnemers van de interactie een potentieel bron van rollenconflicten teweeg brengen.

Rollenconflicten kunnen alleen al daarom ontstaan, omdat sociaal tolken vaak met klanten werken die nog geen eerdere ervaring met tolken hebben en 
daarom niet begrijpen, wat de grondslag van de rol van de tolk is. Net zo kunnen conflicten voortvloeien uit het niet volledig begrijpen van eigen rol door de tolk zelf.

\section{Bibliografie}

Anderson, R., \& Bruce W. (2002): "Perspectives on the role of interpreter". In: Franz Pöchhacker \& Miriam Shlesinger (red.), The Interpreting Studies Reader. London/New York: Routledge, 209-215.

Angelelli, Claudia V. (2003): "The interpersonal role of the interpreter in cross-cultural communication. A survey of conference, court and medical interpreters in the US, Canada and Mexico". In: L. Brunette, G.L. Bastin, I. Hemlin \& H. Clarke (red.), The Critical Link 3: Interpreters in the Community. Amsterdam/Philadelphia: John Benjamins Publishing Company, 15-26.

Angelelli, Claudia V. (2004): Revisiting the Interpreter's Role. A Study of Conference, Court and Medical Interpreters in Canada, Mexico, and the United States. Amsterdam/Philadelphia: John Benjamins.

Bancroft, Marjory (2015): "Community interpreting: A profession rooted in social justice". In: Holly Mikkelson \& Renée Jourdenais (red.), The Routledge Handbook of Interpreting. New York: Routledge, 217-235.

Bot, Hanneke (2003): "The myth of the uninvolved interpreter interpreting in mental health and the developkovment of a three-person psychology". In: L. Brunette, G.L. Bastin, I. Hemlin H. Clarke (red.), The Critical Link 3: Interpreters in the Community. Amsterdam/Philadelphia: John Benjamins Publishing Company, 27-35.

Carr, Silvana E., e.a. (red.) (1997): The Critical Link: Interpreters in the Community. Papers from

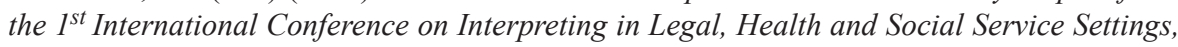
Geneva References 149 Park, Canada, 1-4 June 1995. Amsterdam/Philadelphia: John Benjamins (= Benjamins Translation Library, 19).

Čeňková, Ivana, e.a. (2001): Teorie a didaktika tlumočení. Praha: Univerzita Karlova.

ČSN ISO 13611 (2015): Tlumočnické služby - Směrnice pro komunitni tlumočení. Praha: Ústav pro technickou normalizaci, metrologii a státní zkušebnictví.

De Keyser, Raïssa (2006): Horen, zien en tolken. Werken als tolk in de sociale sector. Gent: Academia Press.

Diabová, Amalaine, e.a. (2014): Chápete, člověče, co vám ř́kám?, aneb Komunitní tlumočení u nás: (Návod, jak se domluvím s uprchlikem, pacientem, neslyšicím...). Praha: Jednota tlumočníků a překladatelů, Generální ředitelství pro překlady Evropské komise \& Komora soudních tlumočníků ČR.

Doornbos, Nienke (2006): Op verhaal komen: institutionele communicatie in de asielprocedure. Nijmegen: Wolf Legal Publishers.

Favaron, Roberta (2010): Interpreting in a Bilingual Healthcare Facility (dissertation), Vienna: University of Vienna, Zentrum für Translationswissenschaft.

Figarová, Anita (2012): Sociaal tolken in Vlaanderen en Tsjechië vanaf 2004: een vergelijking (diplomová práca). Olomouc: Univerzita Palackého v Olomouci, Filozofická Fakulta.

Garber, Nathan (2000): Community Interpretation: A Personal View. In: Roda P. Roberts, Silvana E. Carr, Diana Abraham \& Aideen Dufour (red.), The Critical Link 2: Interpreters in the Community. Selected papers from the Second International Conference on Interpreting in legal, health and social service settings, Vancouver, BC, Canada, 19-23 May 1998. Amsterdam/Philadelphia: John Benjamins, 9-21 (= Benjamins Translation Library, 31). 
Gentile, Paola (2017): "Het zelfbeeld van sociaal tolken, een miskend en onderschat beroep: overzicht van de huidige situatie in Nederland". Internationale Neerlandistiek 55:1, 1-22.

Hale, Sandra Beatriz (2007): Community Interpreting. Basingstoke: Palgrave Macmillan.

Hertog, Erik (2010): “Community interpreting”. In: Y. Gambier \& L. van Doorslaer (red.), Handbook of Translation Studies. Deel 1. Amsterdam/Philadelphia: John Benjamins, 49-54.

Holkupová, Jiřina (2010): The Role of Community Interpreter from the Point of View of Users' Expectations (diplomová práce). Praha: Univerzita Karlova.

Kaufert, Joseph M., \& Robert W. Putsch (1997): “Communication through interpreters in healtcare: Ethical dilemmas arising from differences in class, culture, language, and power". The Journal of Clinical Ethics 8:1,71-87.

Knap-Dlouhá, Pavlína (2015): "De positie van beëdigde tolken en vertalers in Tsjechië en Nederland en een casusonderzoek naar tolken in een interlandelijke adoptieprocedure". Brünner Beiträge zur Germanistik und Nordistik 29:2, 141-149.

Leanza, Yvan (2005): "Roles of community interpreters in pediatrics as seen by interpreters, physicians and researchers". Interpreting 7:2, 167-193.

Macáková, Dita (2018): Sociaal tolken in Nederland en Tsjechië. Een vergelijking (diplomová práce). Olomouc: Univerzita Palackého v Olomouci, Filozofická Fakulta.

Mikkelson, Holly (1996): “Community interpreting: An emerging profession”. Interpreting, International Journal of Research and Practice in Interpreting 1:1, 125-129.

Nakládalová, Lucie (2005): Komunitni tlumočení v azylových zařizeních České republiky (diplomová práce). Praha: Ústav translatologie Filozofické fakulty Univerzity Karlovy.

Phelan, Mary (2001): The Interpreter's Resource. Clevedon: Multilingual Matters.

Pöchhacker, Franz (1999): “Getting organized': The evolution of community interpreting”. Interpreting $4: 1,125-140$.

Pöchhacker, Franz (2000): “The community interpreter's task: Self-perception and provider views". In: Roda P. Roberts, Silvana E. Carr, Diana Abraham \& Aideen Dufour (red.), The Critical Link 2: Interpreters in the Community. Amsterdam/Philadelphia: John Benjamins, 49-65.

Pöchhacker, Franz (2004): Introducing Interpreting Studies. London: Routledge.

Pöchhacker, Franz (2007): "Critical linking up: Kinship and convergence in interpreting studies". In: Cecilia Wadensjö e.a. (red.), The Critical Link 4: Professionalisation of Interpreting in the Community. Selected Papers from the $4^{\text {th }}$ International Conference on Interpreting in Legal, Health and Social Service Settings, Stockholm, Sweden, 20-23 May 2004. Amsterdam/Philadelphia: Benjamins Translation Library, 11-23.

Pöllabauer, Sonja (2004): "Interpreting in asylum hearings. Issues of role, responsibility and power". Interpreting 6:2, 143-180.

Roberts, Roda (2002): "Community interpreting: A profession in search of its identity". In: E. Hung (red.), Teaching Translation and Interpreting 4: Building Bridges. Amsterdam/Philadelphia: John Benjamins Publishing Company, 157-175.

Roy, Cynthia B. (2000): Interpreting as a Discourse Process. New York NY: Oxford University Press.

Swabey, Laurie, \& Paula Gajewski Mickelson (2008): "Role definition. A perspective on forty years of professionalism in sign language interpreting". In: C. Valero-Garcés \& A. Martin (red.), Crossing Borders in Community Interpreting. Definitions and Dilemmas. Amsterdam/Philadelphia: John Benjamins Publising Company, 51-80.

Wadensjö, Cecilia (1998): Interpreting as Interaction. London: Longman.

Neerlandica Wratislaviensia 29, 2019

(C) for this edition by CNS 


\section{Internetbronnen}

(www1): $<$ http://www.agii.be/thema/sociaal-tolken-en-vertalen/sociaal-tolken-en-vertalen/europeesnetwerk-voor-sociaal-tolken-en-vertalen-enpsit\#nederland $>$, laatst geraadpleegd op 25.08.2018.

(www2): $<$ http://agii.be/sites/default/files/bestanden/deontologische_code_sociaal_tolken.pdf $>$, laatst geraadpleegd op 5.05.2019. 